\title{
PARÁSITOS, RESEÑA CRÍTICA \\ UNA NOVEDOSA FORMA DE INTERPRETAR NUESTRA \\ SOCIEDAD Y NUESTRA MENTE
}

\section{PARASITES, CRITICAL REVIEW \\ A NEW WAY TO INTERPRET OUR SOCIETY AND OUR MIND}

\author{
Juan Manuel Arriaga Benítez \\ Facultad de Filosofía y Letras, UNAM. Ciudad de México \\ hector_aquiles_apolo@hotmail.com
}

Recibido: 13 febrero 2020 Aceptado: 07 marzo 2020

Todos somos o hemos sido parásitos de una u otra forma. Parásito es quien vive a expensas de lo ajeno, quien roba incluso bajo los canales de percepción de los demás, quien se inmiscuye en asuntos que no le corresponden o quien, en última instancia, depende del alimento, el dinero o la existencia de su huésped para sobrevivir.

La película surcoreana Parásitos es una compleja y emocionante metáfora sobre todos estos niveles de dependencia a los que las sociedades contemporáneas han obligado a vivir a muchos de los seres humanos. Contrastante, vertiginosa, tensa e, incluso, conmovedora, esa pieza fílmica es un espejo de todo aquello que hemos sido en algún momento o en lo que convertimos a quienes, incluso sin saberlo, nos rodean, dándoles un cariño a vece sobreprotector.

Y es que lo maravilloso de su trama es, precisamente, la diferencia que el guión magistralmente crea entre lo que los personajes saben y lo que la audiencia sabe. Ese conocimiento que tenemos como audiencia contrasta con lo que la familia de clase alta de esta historia desconoce, creando situaciones de tensión dignas de las películas de Alfred Hitchcock, pero llevadas a un extremo en el que el espectador es capaz de involucrarse activamente en las emociones que los personajes generan: empatía, temor, angustia, incertidumbre, por sólo mencionar algunas. Esta película, de hecho, posee un amplio abanico de detonantes emocionales que no sólo condicionan la continuidad de la trama a voluntad del director, sino que convergen en el fin último de la narrativa entera, que se presenta en forma de ironía trágica enunciada bajo una única sentencia con la que 
el guion no deja de acusarnos: no importa quién seas o dónde estés, de algún modo eres o serás un parásito.

Tan esperpéntico ha sido el contraste entre la ignorancia que viven los personajes dentro del filme y el conocimiento de la audiencia, que incluso de él derivan los mensajes más significativos del visionado, encontrándose al mismo nivel del contraste que entremezcla a la adinerada familia Park y a la empobrecida familia Kim y que poco a poco harán que el espectador vaya entendiendo la carga dramática a la que se está sometiendo, sobre todo porque, junto a escenas llenas de tensión y violencia, coexisten giros inesperados y abruptas revelaciones.

Parásitos es un ejemplo de calidad cinematográfica, no únicamente debido a la bien delineada psicología de cada personaje o a su montaje, sino también y sobre todo gracias al guion que la hizo nacer. Bong Joon-ho, su director y guionista, dio muestras de maestría narrativa tanto al cimentar los aspectos que justifican las acciones y las motivaciones de los personajes como al delimitar perfectamente la trama en una unidad de acción que no deja escapar sus formulaciones narrativas, conectando bien estructura y elocución.

Llegado a este punto, quisiera hablar de dos aspectos que me parece oportuno resaltar, dado que considero que son los que le proporcionan a esta joya del cine surcoreano y mundial su significado e impulsan al espectador hacia el subtexto 1 en el que está basado su metafórico despliegue narrativo.

El primer aspecto a reseñar parte de la pregunta: ¿Quiénes son los parásitos? Como antes afirmé, parásitos somos todos los seres humanos, debido a la construcción en la que se fundamentan nuestras sociedades, haciéndonos depender de muchas cosas: desde que nacemos, dependemos del cobijo familiar para desarrollarnos física y mentalmente, y a medida que crecemos nos volvemos parásitos del gobierno, del cariño

\footnotetext{
1 El subtexto es un campo de estudio de la narrativa fílmica (y literaria en general) por medio del cual es posible comprender que hay niveles de significación en un texto, es decir, la función connotativa que deriva de la interpretación que se hace sobre él. Los subtextos, como los define el maestro de guión Robert Mckee, son "la vida que se oculta bajo la superficie - los pensamientos y sentimientos, tanto conocidos como desconocidos, ocultos tras ese comportamiento" (1997, 305). Para mayor información sobre subtexto, véase Gérard Genette Palimpsestos. La literatura en segundo grado (edición de 1989) y David Bordwell Making Meaning. Inference and Rhetoric in the Interpretation of Cinema (edición de 1989).
} 
ajeno, del prestigio, de la moral pública y, lo que me comunica la película más a fondo, de la información. Siguiendo este razonamiento, me parece que Parásitos es una película que critica a los medios de comunicación, pues el despliegue mediático al que está subordinada la información que consumimos en la televisión, el cine o el internet está condicionada por quienes la manejan: la elocución mediática, por mucho que pretenda ser imparcial, presenta siempre sesgos; la familia Kim, con todo y que provienen de un barrio pobre y viven al día, es la encargada de representar a los medios de comunicación, pues producen (falsa) información para lograr sus objetivos y construyen, a lo largo de la película, un punto ciego en el que los miembros de la familia Park fundamentan sus pensamientos.

El segundo de esos aspectos que dotan de significado a la película es la fuerza gravitatoria que ejerce sobre toda la trama, desde su aparición, el sótano de la casa. Presentado primero como un lugar donde vive oculto el marido de la primera ama de casa, ese sitio comienza paulatinamente a tomar una relevancia preponderante, pues adquiere connotaciones siniestras que lo establecen incluso como otro de los personajes de la trama; en efecto, ese sótano tiene un simbolismo muy apegado a la idea del subconsciente humano, donde las frustraciones y recelos de la mente se ocultan como auténticos parásitos y sacan lo peor de cada quien en los momentos en los que esos secretos salen a la luz o son puestos en peligro. En calidad de subconsciente, el sótano queda, al final, entendido como un refugio, si es que logramos entender que en ese rincón de la psique se pueden contener los rasgos de nuestra verdadera personalidad y que, por más que luchemos contra ellos, siempre terminarán encontrando vías de escape. Lo que nos hace parásitos en este mundo contemporáneo está, según esta interpretación, en nuestra propia mente, por lo que es mejor convivir con ese mundo subterráneo que volvernos seres destructivos, como precisamente se dibuja en la trama a través de la trágica escena de violencia que desencadena el final de la historia.

En conclusión, Parásitos es una película que no sólo puede verse como la intervención de una familia en la vida ajena o como la dependencia que se fomenta a través del diseño de nuestras sociedades, sino que también adopta una profundidad narrativa al criticar a los medios de comunicación y al proponer una interpretación del 
subconsciente humano como un sitio aislado y hondo en cuyos pasillos habitan esos parásitos reprimidos que moldean nuestra personalidad.

Sin duda, una cumbre cinematográfica que, estoy seguro, puede convertirse en un referente sobre cómo moldear tramas complejas en las que se vuelcan situaciones de vida cotidiana, tensiones emocionales y significados ingeniosamente cuidados.

\section{FICHA TÉCNICA}

기생충 (Gisaengchung), Corea del sur, 2019.

Dirección: Bong Joon-ho.

Guión: Bong Joon-ho.

Reparto: Song Kang-ho, Lee Sun-kyun, Cho Yeo-jeong, Choi Woo-shik, Park So-dam. Duración: 132 min.

Premios y reconocimientos: Ganadora de la Palma d'or en el Festival Internacional de Cine de Cannes; premio a la mejor película extranjera y mejor director en los Golden Globes 2020; ganadora de 4 premios de la Academia de Artes y Ciencias Cinematográficas (Óscares 2020) a mejor película extranjera, mejor director, mejor guión original y mejor película del 2019.

\section{REFERENCIAS BIBLIOGRÁFICAS2}

Bordwell, David (1989). Making Meaning. Inference and Rhetoric in the Interpretation of Cinema. USA: Harvard University Press.

Genette, Gerard (1989). Palimpsestos. La literatura en segundo grado. (C. F. Prieto, Trad). España: Taurus.

Mckee, Robert (1997). El guión. Sustancia, estructura, estilo y principios de la escritura de guiones. (J. Lockhart, trad.). España: Alba.

Meléndez, Javier (S. F.). “4 ejemplos de subtexto en guión”. La solución elegante. Recuperado de https://lasolucionelegante.com/subtexto/

\footnotetext{
2 Estas consultas constituyen un núcleo teórico general que me permitió interpretar la película del modo en que lo he hecho y que pueden proporcionar al lector una profundización más acorde no sólo con ésta, sino con alguna otra película, por lo que son herramientas fundamentales en el estudio de narrativa e interpretación.
} 
Mitry, Jean (1986). Estética y psicología del cine. (Palacios More, R., trad.). Madrid: Siglo XXI Editores.

Premiere Actors. (24 sep., 2014). "Diferencia entre texto, contexto y subtexto". Premiere Actors. Recuperado de http://www.premiereactors.com/diferencia-entre-texto-contextoy-subtexto/

Rodríguez, Alfonso M. (2017). El uso del subtexto como propaganda machista en el personaje de Lois Lane en Man of steel (Zack Snyder, 2013). Ex Аеquo, 35, 159-171. 